\title{
Endocarditis associated with blood fluke infections (Digenea: Aporocotylidae: Psettarium cf. anthicum) among aquacultured cobia (Rachycentron canadum) from Nha Trang Bay, Vietnam
}

Micah B. Warren ${ }^{\mathbf{a}}$, Raphael Orélis-Ribeiro ${ }^{\mathbf{a}}$, Carlos F. Ruiz ${ }^{\mathbf{a}}$, Binh T. Dang ${ }^{\mathbf{b}}$, Cova R. Arias ${ }^{\mathbf{c}}$, and Stephen A. Bullard ${ }^{\mathbf{a}_{*}}$

a Auburn University, School of Fisheries, Aquaculture, \& Aquatic Sciences and Aquatic Parasitology Laboratory, 203 Swingle Hall, Auburn, AL, 36849

${ }^{\mathbf{b}}$ Nha Trang University, Department of Biology, Institute for Biotechnology and Environment, 02 Nguyen Dinh Chieu Street, Nha Trang City, Vietnam

${ }^{\mathbf{c}}$ Auburn University, School of Fisheries, Aquaculture, \& Aquatic Sciences and Aquatic Microbiology Laboratory, 559 Duvall Drive, Auburn, AL, 36832

*Corresponding author: SA Bullard, 203 Swingle Hall, Auburn University, 334-844-9278 (phone), 334-844-9208 (fax), ash.bullard@auburn.edu

\begin{abstract}
We herein diagnose blood fluke (Digenea: Aporocotylidae) infections in sea cagereared cobia (Rachycentron canadum) from Nha Trang Bay, Vietnam, using morphology, nucleotide sequences, scanning electron microscopy, and histopathology. This is the first report of this blood fluke beyond the Gulf of Mexico and contributes to our understanding of the disease implications of aporocotylid infections among marine aquacultured fishes. Blood flukes were morphologically identified as Psettarium cf. anthicum by having the combination of an extremely elongate body with rows of straight, ventrolateral tegumental spines and a sinistral posterolateral protuberance, an H-shaped intestine with asymmetrical posterior ceca, a lobed ovary, an ootype posterior to the male genital pore, and an extensively convoluted uterus located between the ovary and ootype. A comparison of the large subunit ribosomal DNA (28S), small subunit ribosomal DNA (18S), and internal transcribed spacer 2 (ITS2) derived from blood flukes infecting cobias in Nha Trang Bay and Gulf of Mexico revealed 5 (99.5\% similarity in 28S), $3(99.8 \%, 18 S)$, and 12 (98.9\%, ITS2) nucleotide differences between the geographic isolates. Adult blood flukes pierced the endocardium and penetrated the spongy myocardium or lesioned endocardium of the cobias from Nha Trang Bay. The associated heart lesion comprised fibro-granulomatous endocarditis with accompanying endocardial thrombi, including focal effacement of the endocardium adjacent to thrombi, hyperplasia of endocardial cells yielding a thickened endocardium within which adult flukes resided or fluke remnants were located, clusters of large epitheliod granulomas within thrombi and within the basal endocardium, and minute granulomas in spongy myocardium enclosing probable blood fluke eggs. These pathological alterations suggested that heavily-infected cobia may suffer reduced cardiac output via thrombi blocking normal blood flow and emboli causing infarcts. Acute mortality may be likely for heavily-infected cobias during periods of high cardiac output, e.g., during feeding in a sea cage, if concomitant with, or resulting in, circulation of emboli. The lesioned endocardium may reduce efficiency of respiratory gas exchange to cardiac myocytes as well as impair endocardial cell immune function.
\end{abstract}

Key words: Aquaculture, disease, cobia, blood fluke, emboli, thrombi, endocarditis, pathology

\section{Introduction}

Cobia, Rachycentron canadum, (Perciformes: Rachycentridae) is a pantropical (except eastern Pacific Ocean) migratory fish capable of transiting low salinity estuaries and offshore 
pelagic waters (Shaffer and Nakamura, 1989). It is commercially-prized because of its rapid growth rate, good overall aquaculture performance, and desirability as table fare; especially in Taiwan and Japan (Liao et al., 2004; Benetti et al., 2008; Nhu et al., 2011; Petersen et al., 2014). Cobia comprises a prized sportfish in various part of its range, particularly in littoral waters of the United States where active recreational sport fisheries exist in the Gulf of Mexico and northwestern Atlantic Ocean (Shaffer and Nakamura, 1989). Aquaculture of cobia in sea cages is a large and rapidly expanding industry in Asia, where cobia is among the most popular of the cage-cultured fish species. Large scale aquaculture production of cobia began in Taiwan in the 1970's; grow-out from wild-caught fingerlings began in 1993-1995; the first captive reproduction occurred in 1994; and the first mass production commenced in 1997 (Liao et al., 2004; Nhu et al., 2011). At least 23 countries now grow cobia (FAO, 2009; 2012; Phinchongsakuldit et al., 2013), with total production increasing from 9 tons in 1997 to $>30,000$ tons in 2007 (FAO, 2009; 2012).

Vietnam likely comprises the world's $3^{\text {rd }}$ largest producer of cobia $(\sim 1,500$ and $\sim 2,600$ tons produced in 2008 and 2009, respectively) behind China (>25,000 tons annual production) and Taiwan (4,000 tons annual production) (FAO, 2009; Nhu et al., 2011; Huang et al., 2011). Production in Vietnam, which relies on both domestically-raised and imported fingerlings from China and Taiwan (Huang et al., 2011), is split between a large number of small-scale, familyoperated farms that furnish cobia for local consumption as well as medium- and large-scale cooperatives that utilize traditional cages or high density polyethylene (HDPE) floating cages for grow-out (Nhu et al., 2011; Petersen et al., 2014). Cobia aquaculture operations vary in scale and methodology, but, in general, adult fish are hormonally induced to spawn in breeding tanks, and resulting larvae and fingerlings are reared in closed recirculating systems and outdoor ponds before eventually being moved to the large sea cages (Benetti et al., 2008; Nhu et al., 2011; Petersen et al., 2014). The one year growing cycle yields $6-8 \mathrm{~kg}$ individual cobia, which are sold whole for local consumption in southeast Asian markets; whole or headless for the Japanese sashimi market; or filleted for western markets (Liao et al., 2004).

As they do for seemingly most finfish aquaculture sectors (Blaylock and Bullard, 2015), infectious diseases constrain cobia aquaculture. Liao et al. (2004) cited a "high incidence of disease outbreaks" throughout all phases of the cobia aquaculture cycle and identified diseaseinduced mortality as an ongoing threat to the industry as a whole. At present, specific information on the etiology of 'choke point diseases' (those constraining aquaculture production), particularly during cobia grow-out in sea cages, is predominantly lacking. Within sea cages, young cobia can be decimated by diseases variously linked to the occurrence/infection by an array of viruses, bacteria, and metazoan parasites (e.g., Shaffer and Nakamura, 1989; Chen et al., 2001; Liao et al., 2004; Bunkley-Williams and Williams, 2006; Lowry and Smith, 2006; Ogawa et al., 2006; Chu et al., 2013; McLean et al., 2013; Estrada et al., 2015). Although these symbionts are not documented to cause disease among wild cobia, they take on pathogen status when environmental conditions and fish physiological status are appropriate for the onset of disease.

Fish blood flukes (Platyhelminthes: Digenea: Aporocotylidae) comprise surveillance-worthy parasites for marine aquaculturists operating sea cages (Bullard and Overstreet, 2002; 2008; Orélis-Ribeiro et al., 2014 and references therein). This is especially true for high-value aquaculture species like amberjacks (Seriola spp.) (Ogawa and Egusa, 1986; Ogawa et al., 1989; Crespo et al., 1992; Grau, 1994; Ogawa et al., 1993; Ogawa and Fukudome, 1994; Gonzalez et al., 1995; Montero et al., 2003) and tunas (Thunnus spp.) (Munday and Hallegraeff, 1998; 
Colquitt et al., 2001; Munday et al., 2003; Aiken et al., 2015; Shirakashi et al., 2016). Aporocotylids have a 2-host life cycle that requires an invertebrate intermediate host and a fish definitive host (Køie, 1982; 1988; Kirk and Lewis, 1993; 1992; Bullard and Overstreet, 2008). Clonal, asexual reproduction occurs in the snail, bivalve, or polychaete intermediate host; producing a multitude of infective fluke larvae (cercariae) that are free-swimming and directly penetrate fish epithelia. Once the fluke makes contact with the host, it sheds its cercarial tail, migrates to infect the blood vascular system, matures, copulates, and releases eggs; which typically are then carried to the branchial arterioles via the blood vascular system before transiting the blood vessel wall and undergoing considerable larval development in the gill epithelium. The eggs are ejected from or hatch in gill epithelium before the larva (miracidium) infects the intermediate invertebrate host. Because of this life cycle, high intensity fish blood fluke infections may result when both fish and invertebrate hosts reside in close proximity, as happens in some aquaculture scenarios. Such intense infections may induce respiratory impairment from adults or eggs that occlude branchial vessels (Thulin, 1980; Colquitt et al., 2001; Munday et al., 2003) or from eggs, miracidia, or cercariae that damage the gill epithelium upon exiting or entering the fish host (Crespo et al., 1992; Kirk and Lewis, 1992; Herbert et al., 1995, Bullard and Overstreet, 2002; 2008). If or how these epithelial insults hasten the onset of secondary bacterial infections is indeterminate but other digenean-fish interactions indicate that digenean cercarial penetration can be highly pathogenic (Overstreet and Curran, 2004). Hence, fish blood flukes are important as primary pathogens but also worthy of investigation as promoters of secondary bacterial infection.

Despite the economic importance of cobia aquaculture in Asia and the documented pathological effects of blood fluke infections on cage-cultured marine fishes (see above), no information exists about the taxonomic identity, occurrences, or pathobiology of blood fluke infections in cage-cultured cobia. Herein, we use a combination of light and scanning microscopy, complementary histopathology, and molecular biology to diagnose and characterize a blood fluke (Psettarium cf. anthicum Bullard and Overstreet, 2006) infection in the heart of several cage-cultured cobia from Nha Trang Bay, Vietnam. This is the first report of $P$. cf. anthicum from the Pacific Ocean or from an aquaculture setting (Bullard and Overstreet, 2006). It is only the second report of a marine fish blood fluke infection in Vietnam (Orélis-Ribeiro et al., in review).

\section{Materials and methods}

\subsection{Field collection and fixation of specimens}

Five fresh-dead cobia (760-810 $\mathrm{mm}$ fork length; estimated weight approximately $4 \mathrm{~kg}$ [see Benetti et al. [2011]; harvested from a Nha Trang Bay sea cage) were purchased from the Vĩnh Hải Fish Market (12¹6'44.8"N; 109 $\left.11^{\prime} 38.9^{\prime \prime} E\right)$ (Nha Trang, Vietnam) and necropsied during June 2015. The cobias, which were being sold as food fish, were assessed as 'fresh-dead' principally by the presentation of their eyes (clear, not opaque), gill filaments (intact, regularly arranged in an array, bright red in color, lacking extensive mucus or evidence of autolysis), and somatic muscle (intact, firm, lacking foul odor) as well as by the resulting cardiac histopathology that lacked evidence of putrefaction. The heart was excised, immersed within a glass dish containing physiologic saline, bisected to expose the lumen, and examined with the aid of a stereo-dissecting microscope and fiber optic light source. Examined cobias were infected (5 of 5; prevalence $=100 \%)$ with $2-5($ mean density $=4)$ live adult flukes each and had $1-5($ mean $=3)$ endocardial thrombi each. Live flukes intended as whole-mounts and for scanning electron microscopy (SEM) were excised from cardiac muscle and placed in a vial of 5-10\% neutral 
buffered formalin (n.b.f.); whereas, those for DNA analysis were placed in $95-100 \%$ ethanol $(\mathrm{EtOH})$ and stored at $-20^{\circ} \mathrm{C}$ until DNA was extracted. Portions of cardiac muscle intended for histopathology and SEM were preserved in $10 \%$ n.b.f.. Voucher specimens of the blood flukes reported herein from Vietnam were deposited in the Smithsonian Institution's National Museum of Natural History (United States National Museum collection numbers [note to reviewer: these will be routinely assigned upon manuscript acceptance] XXXXXX-X).

\subsection{Light and scanning electron microscopy}

Blood fluke specimens for morphology were partly excised from n.b.f.-fixed hearts by clipping the anterior and posterior ends of the flukes (Figs. 1-6), rinsed with distilled water, stained overnight in Van Cleave's hematoxylin with several additional drops of Ehrlich's hematoxylin, made basic in $70 \% \mathrm{EtOH}$ with lithium carbonate and butyl-amine, dehydrated, cleared in clove oil, and permanently mounted in Canada balsam. Illustrations of stained, mounted specimens were made with aid of a Leica DM-2500 (Leica, Wetzler, Germany) equipped with differential interference contrast (DIC) optical components and a drawing tube. Measurements were obtained with a calibrated ocular micrometer and are herein reported in micrometers $(\mu \mathrm{m})$ followed by their mean and the number measured in parentheses. Scientific names including taxonomic authorities and dates for fishes follow Eschmeyer et al. (2016). Common names are taken from FishBase (Froese and Pauly, 2016). Nomenclature for Aporocotylidae follows Bullard et al. (2009). Specimens for morphology with SEM were washed with de-ionized water, dehydrated through a graded EtOH series, critical point dried in liquid $\mathrm{CO}_{2}$, mounted on SEM aluminum stubs with double-sided carbon tape, sputter-coated with gold palladium (19.32 $\left.\mathrm{g} / \mathrm{cm}^{3} ; 25 \mathrm{~mA}\right)$, and viewed with a Zeiss EVO 50VP SEM. Type and voucher materials are deposited in the United States National Museum (USNM, Washington, D.C.).

\subsection{Molecular biology}

Total genomic DNA was extracted from one blood fluke from Nha Trang Bay cobia and one from Gulf of Mexico cobia using DNeasy ${ }^{\mathrm{TM}}$ Blood and Tissue Kit (Qiagen, Valencia, CA) according to the manufacturer-recommended protocol, except that the incubation period with proteinase-K was extended overnight and only $100 \mu$ l of elution buffer was used in the final elution step to increase the final DNA concentration in the eluate. Amplification of the large subunit ribosomal DNA (28S), small subunit ribosomal DNA (18S), and internal transcribed spacer 2 (ITS2) regions used the following primer sets: 28S rDNA- U178 [F] and L164 [R]; 18S rDNA- 18SE (alias 18S-A) [F] and Worm B [R]; ITS2 rDNA- ITS2.2 [R] and GAI [F] (see Anderson and Barker, 1998; Cribb et al., 1998; Littlewood and Olson, 2001; Lockyer et al., 2003; Orélis-Ribeiro et al., 2014). PCR amplifications were carried out in a total volume of $25 \mu 1$ of a solution containing $2 \mu \mathrm{l}$ of DNA template, $0.4 \mu \mathrm{M}$ of each primer along with $1 \times$ buffer, 2.5 $\mathrm{mM} \mathrm{MgCl} 2$ (New England Biolabs, Ipswich, MA), $1 \mathrm{mM}$ dNTP mixture, and $0.3 \mu \mathrm{Taq}$ polymerase (5 U/ $\mu \mathrm{l})$ (New England Biolabs). The 18S and 28S rDNA amplification reactions were performed with a cycling profile of 4 min at $94^{\circ} \mathrm{C}$ for initial denaturation, followed by 40 repeating cycles of $94^{\circ} \mathrm{C}$ for $40 \mathrm{~s}$ for denaturation, $50^{\circ} \mathrm{C}$ for $30 \mathrm{~s}$ for annealing, and $72^{\circ} \mathrm{C}$ for 2 min for extension, followed by a final $7 \mathrm{~min}$ at $72^{\circ} \mathrm{C}$ for extension. The ITS 2 rDNA amplification reactions were performed with a cycling profile of $4 \mathrm{~min}$ at $94^{\circ} \mathrm{C}$ for initial denaturation, followed by 40 repeating cycles of $94^{\circ} \mathrm{C}$ for $40 \mathrm{~s}$ for denaturation, $50^{\circ} \mathrm{C}$ for $30 \mathrm{~s}$ for annealing, and $72^{\circ} \mathrm{C}$ for $1 \mathrm{~min}$ for extension, followed by a final $5 \mathrm{~min}$ at $72^{\circ} \mathrm{C}$ for extension. All PCR reactions were performed in a Veriti Thermal Cycler (Applied Biosystems). PCR products $(5 \mu \mathrm{l})$ were verified on a $1 \%$ agarose gel and stained with ethidium bromide. PCR amplicons were gel-excised using QIAquick ${ }^{\mathrm{TM}}$ Gel Extraction Kit (QIAGEN) following the manufacturer's 
protocol. Bidirectional DNA sequencing was performed by GENEWIZ with ABI Prism 3730xl DNA analyzer (GENEWIZ, Inc., South Plainfield, NJ). Sequences were assembled, manually checked for accuracy, and aligned with BioNumerics version 7.0 (Applied Maths, Saint-MartensLatem, Belgium).

Nucleotide sequence data reported in this paper are available in the GenBank database under submission ID numbers KX840320, KX840319, and KX840318 for Psettarium cf. anthicum 18S, 28S, and ITS2 (respectively) as well as KX840315, KX840316, and KX840317 for Psettarium anthicum 18S, 28S, and ITS2, respectively.

\subsection{Histopathology}

Infected cobia hearts were removed from n.b.f. after 7 days, rinsed in de-ionized water for 2 hours, grossed to focus on endocardial thrombi and lesioned endocardium, processed routinely for histology by dehydration in an EtOH series, embedded under vacuum pressure in paraffin, sectioned at $4 \mu \mathrm{m}$, mounted on glass slides, de-paraffinized, routinely stained with hematoxylin and eosin, and photographed with aid of a compound light microscope. A total of 8 tissue blocks generated approximately 1,134 paraffin sections mounted on 162 glass slides. Nomenclature for heart pathology follows Poppe and Ferguson (2006).

\section{Results}

\subsection{Morphological diagnosis of Psettarium cf. anthicum (Figs. 1-4)}

Description (based on 8 partial, permanently-mounted specimens and 3 partial specimens mounted for SEM; USNM Coll Nos. XXXXXX-X): Body thin, flat, ventrally concave, extremely elongate, having sinistral posterolateral body protuberance, $350-760(495 ; 8)$ in maximum width at level of testis, mesoparasitic in wall of atrium and ventricle, with middle region of body embedding within myocardium, with anterior end and posterior end extending into lumen of heart; anterior body half comprising mouth, anterior sucker, esophagus, intestine, and anterior portion of vitellarium; posterior body half comprising gonads and genitalia, laterally bent (slightly hooked) in posterior extremity, having rounded end, including posterolateral protuberance; posterolateral protuberance extending 50-95 $(64 ; 5)$ laterad from body margin, 120-245 (166; 5) wide at base, 540-920 (710; 4) from posterior body end (Figs. 1-4). Tegument rugose, spined; body spines each 5 (2) long, 3 (2) wide, distributing in rows, fused or rosethornshaped spines absent; tegumental spine rows consisting of 138-166 (2) rows per side of body or 276-332 (2) total rows (a juvenile specimen had 66-72 [1] rows per side of body or 138 [1] total rows distributing to the posterior body end), each 18-23 (2) in breadth, with number of spines per row increasing from anterior end of body mediad, with number of spines per row decreasing from medially portion of body posteriad, comprising 7-8 (2) spines anteriorly, comprising 10-11 (2) spines medially, comprising 5-7 (2) spines posteriorly (Fig. 1). Nerve cords and nerve commissures indistinct. Ventral tegumental sensory papillae abundant on body surface posterior to level of posterolateral protuberance only, 14-33 (2) in number, 8 (2) long, 8-10 (2) wide at base, each evidently lacking sensory cilium.

Mouth medioventral, subterminal, minute, 5 (1) in diameter, centering on a slightly muscular anterior sucker lacking spines. Pharynx absent. Esophagus extending directly posteriad along midline, 1,410-1,430 (2) long, 3-10 (2) wide near mouth, 18-60 (2) wide in middle portion, 28-38 (2) posteriorly at level of cecal bifurcation, having up to 3 curves; esophageal wall 3 (2) thick near mouth, 8 (2) thick in posterior portion at level of cecal bifurcation; esophageal gland enveloping esophagus immediately anterior to cecal bifurcation, concentrated in an area 153 (1) long or $10 \%$ of esophageal length and 53 (1) in maximum width (Fig. 1). Intestine H-shaped, having a cecal bifurcation plus paired anterior (short) and posterior (long) ceca, containing 
granular material within lumen; granular material dense, brownish yellow in wholemounts, sporadically filling cecal lumen; anterior ceca short, approximately equal in length, lacking lateral projections, 210 (2) long, 45 (2) wide, with each cecum extending short distance anteriad between esophagus and body margin, not reaching level of esophageal gland; posterior ceca asymmetrical, sinuous, having lateral projections (but not markedly thorn-like); dextral posterior cecum 1,225 (1) long or 5.8x dextral anterior cecum length (dextral posterior cecum damaged), 95 (1) wide, lacking thorn-like projections posteriorly; sinistral posterior cecum 1,005 (1) long or 5.7x sinistral anterior cecum length (sinistral posterior cecum damaged), 60 (1) wide, lacking thorn-like projections posteriorly; cecal bifurcation 75 (1) from anterior end (Fig. 1).

Testis medial, extensive, single, post-cecal, having breadth approximately equal to maximum body width, in posterior body half. Vasa efferentia indistinct. Vas deferens extending 420-725 $(620 ; 6)$ posteriad from posterior margin of testis, ventral to testis and ovary, slightly lateral to midline in sinistral half of body, 5-25 $(14 ; 6)$ in maximum width, approximately straight (not coiled or extensively convoluted along course posteriad), connecting with cirrus sac medially at level immediately anterior to posterolateral body protuberance (Figs. 2-4). Auxiliary external seminal vesicle absent. Cirrus sac post-gonadal, sinistral, 213-375 $(281 ; 6)$ long, 85-110 $(97 ; 6)$ in maximum width, having wall 5-10 $(6 ; 5)$ thick, enveloping seminal vesicle and cirrus; seminal vesicle $278-375(326 ; 6)$ long, $45-105(70 ; 6)$ in maximum width or $12-19 \%$ of maximum body width, having wall 5 (5) thick, post cecal, post-gonadal, orienting towards sinistral body margin, containing sperm in all observed specimens, having putative glandular cells surrounding distal end; putative glandular cells basophilic, collecting ducts and surrounding membrane indistinct; ejaculatory duct $113-205(153 ; 5)$ long or $31-65 \%$ of seminal vesicle length, $13-30(20 ; 5)$ wide or $17-50 \%$ of seminal vesicle width, having wall approximately 5 $(4.5 ; 6)$ thick; cirrus everting on lateral margin at apex of posterolateral body protuberance, finger-like, 110-140 (131; 6) long; post-cirrus space 650-1300 (982; 6) long (Figs. 2-4).

Ovary medial, post-cecal, post-testicular, lobed, 140-300 $(245 ; 6)$ long, 315-455 $(409 ; 6)$ wide or $72-90 \%$ of maximum body width, dorsal to vas deferens, occupying space immediately posterior to testis (Figs. 2-4). Laurer's canal absent. Oviduct 710-1125 (919; 5) long, 13-28 (21; 5 ) wide, originating from posterior margin of ovary, extending directly posteriad $425-1,010$ $(698 ; 4)$ between uterus and dextral body margin,13-28 $(19 ; 5)$ in diameter (Figs. 2-4). Common vitelline duct and oviduct extending posteriad between uterus and dextral body margin. Vitellarium comprising an extensive network of narrow interconnecting branching bands, distributing from anterior body end posteriad to beyond level of gonads and genitalia, ventral to alimentary tract and testis, secondary collecting ducts indistinct; primary vitelline collecting duct ventral to gonads, extending sinuously posteriad $750-1,425(1138 ; 5)$ from testis and between uterus and dextral body margin, $25-55(38 ; 6)$ in maximum width at level of ovary, joining distal portion of oviduct anterolaterally and forming short common duct before merging with oötype; oötype medial, near posterior body end, posterior to gonads and remaining genitalia, spheroid. Mehlis' gland indistinct. Uterus comprising ascending and descending portions; ascending portion of uterus extending directly anteriad from oötype and between cirrus sac and oviduct plus primary vitelline collecting duct, becoming extensively convoluted at level of female genital pore, occupying space primary between ovary and oötype, 20-40 $(30 ; 5)$ wide near oötype, $40-75(57 ; 6)$ in maximum width or $9-13 \%$ of body width, arching sinstrad immediately posterior to ovary and connecting with descending portion of uterus; descending portion of uterus less convoluted, extending posteriad, terminating immediately anterior to cirrus sac; uterine eggs spheroid, filling lumen of uterus for entire length, having thin membrane, lacking 
thickened shell, 3-18 $(11 ; 6)$ in diameter or 5-36\% of uterus maximum width, with largest eggs within distal portion of descending uterus, which may comprise a weakly muscular metraterm (Figs. 2-4). Female genital pore sinistral, dorsal, anterior to male pore, 10-20 $(14 ; 5)$ wide, $740-1,550(1128 ; 4)$ from posterior body end, opening dorsally at level of junction of vas deferens and cirrus sac (Figs. 2-4). Excretory system indistinct.

\subsection{Molecular diagnosis of Psettarium cf. anthicum}

Partial sequences from the large subunit ribosomal DNA (28S) (1,521 nucleotides), small subunit ribosomal DNA (18S) (1,833 nucleotides), and internal transcribed spacer 2 (ITS2) (540 nucleotides) from a specimen of $P$. cf. anthicum infecting a Nha Trang Bay cobia were compared with those derived from a specimen of $P$. anthicum infecting a Gulf of Mexico cobia. Sequence similarity between the specimens was $99.5 \%$ (5 nucleotide differences), $99.8 \%$ (3), and $98.9 \%$ (12), for 28S rDNA, 18S rDNA, and ITS2, respectively.

\subsection{Pathology (Figs. 5-18)}

Gross observations revealed that the mode of attachment of $P$. cf. anthicum in cultured cobia from Nha Trang Bay resembled that of $P$. anthicum infecting wild cobias from the Gulf of Mexico (Bullard and Overstreet, 2006). The adult fluke pierces the endocardium and threads itself through the spongy myocardium or the lesioned endocardium (Figs. 5, 6). It is apparently stationary as an adult, rather than actively crawling about within the lumen of the heart, which is typical for many other blood flukes (Bullard and Overstreet, 2002; 2008). Once the middle portion of the body is embedded, its anterior end (mouth) and posterior end (genital pores) dangle free within the heart lumen (Figs. 5, 6). An obvious, grossly visible host encapsulation comprising an endocardial protuberance (thrombus) envelopes the living parasite at its attachment site and extends from the endocardium and into the lumen of the heart; perhaps causing significant obstruction (Figs. 7-10). Some thrombi harbored one (Figs. 5, 6) or several live adult blood flukes; whereas, others marked foci of fluke remnants (Figs. 7, 8). The approximate size of each thrombus appeared to be proportional to the density of focal infection, but each live adult fluke, regardless of density of infection, elicited a comparable host response. Viewed with SEM, thrombi were variously irregularly-shaped (Figs. 5-8) but ranged from knobby, dendritic masses approximately 2-4 $\mathrm{mm}$ in greatest length (Figs. 5-7) to clusters of oblong to spheroid masses 1-3 mm in greatest width (Fig. 8). Focal effacement of the endocardium and myocardial trabecular surface (Fig. 7) were associated with thrombi (Figs. 711).

Histopathology revealed severe fibro-granulomatous endocarditis, including hyperplasia of endocardial cells creating a much thickened endocardium within which the adult fluke resided or fluke remnants were located (Figs. 9-15). This lesion included focal alteration of myocardial trabeculae adjacent to thrombi such that the endocardium appeared uneven and mounded (Figs. 7-10). Thrombi comprised clusters of large epitheliod granulomas, each enclosing fluke remnants that appeared with hematoxylin and eosin as dense golden-brown masses (Figs. 9, 10, 13). In addition to those observed within thrombi, granulomas enclosing fluke remnants were observed deeper within the lesioned endocardium, in apposition to the spongy myocardium (Figs. 11, 12, 14). Loss of muscle striation in the apical portion of the spongy myocardium (Fig. 15) and evidence of fibrinoid necrosis (Fig. 16) in myocardium were observed. Melanin-like pigment was observed in some sections, suggesting the presence of melanomacrophage aggregates (Fig. 16). A few minute granulomas in spongy myocardium enclosed probable blood fluke eggs (Fig. 17); however, these granulomas were disassociated with a marked host response compared to that of the adult blood flukes in the endocardium (Figs. 7-15). The myocardium 
lacked evidence of "multinucleate nests" (sensu Poppe and Ferguson [2006]), the presence of which indicate extensive regeneration of cardiac myocytes, and the compact myocardium appeared normal. SEM of the thrombus surface revealed that endocardial cells overlay probable fibrinous inflammation (Fig. 18). The degree of endocardial sloughing may have been artifactitiously enhanced by SEM preparation but, nevertheless, also suggests a degree of endocardial sloughing as a pathological change associated with these blood fluke infections.

\section{Discussion}

We identified our blood fluke specimens from Nha Trang Bay cobias as Psettarium cf. anthicum because our specimens were morphologically indistinguishable from the published description and vouchers plus paratype specimens of Psettarium anthicum Bullard and Overstreet, 2006 from Gulf of Mexico cobias. Our reservations about definitively identifying these specimens as $P$. anthicum follow. First, we lacked access to an intact adult specimen because this blood fluke embeds in myocardium such that excising the middle portion of the specimen requires destruction of the surrounding cardiac tissue, which would eliminate the sample for histopathological processing and study. Second, we sequenced a single specimen from each region, i.e., Nha Trang Bay vs. Gulf of Mexico, and the results of those molecular comparisons revealed considerable genetic differences between the geographic isolates. Third, and related to the previous reservations, our results from morphology indicate conspecificity but results from molecular sequence comparisons could be interpreted as indicative of distinct species. Indeed, the molecular sequence differences between these flukes were surprising in light of the high degree of morphological similarity between the specimens. For example, a difference comprising 1-11 ITS2 base differences has been interpreted as a species-level difference for particular blood flukes (see Orélis-Ribeiro et al., [2014] and Nolan et al. [2016] and references therein). Moreover, the $18 \mathrm{~S}$ and $28 \mathrm{~S}$ are considered to be more highly conserved, and differences there suggest distinct lineages/species. Yet, much remains to be learned about how these genetic markers vary across different digenean groups, including fish blood flukes and especially among putative blood fluke populations exploiting hosts with pantropical distributions. Fourth, we acknowledge some inherent bias on our behalf in identifying as conspecific parasites with complex life cycles and that infect non-vagile fish sampled in different ocean basins (western Pacific Ocean vs. Gulf of Mexico); especially in light of the marked molecular differences between the geographic isolates. Additional collections and resulting specimens from Vietnam may reveal morphological details that warrant naming a new species for the specimens we describe herein but that is premature without additional morphological and molecular sequence data. Regardless, these specimens are closely-related species, if not conspecific.

If the blood flukes infecting cobia are indeed conspecific, this would be interesting as it would comprise a first example of a widely-distributed (different ocean basins) fish blood fluke that infects a littoral, relatively non-vagile, non-epipelagic fish species. The intensively studied Cardicola forsteri Cribb, Daintith, and Munday, 2000, for example, also has a wide geographic distribution (Cribb et al., 2000; Bullard et al., 2004; Aiken et al., 2007; Shirakashi et al., 2016); however, this fluke infects epipelagic tunas (Thunnus spp.) that are highly vagile, capable of crossing ocean basins in a lifetime. Conspecificity would further mandate that the life cycle of these blood flukes utilizes different snail, bivalve, or polychaete intermediate hosts or that, seemingly less likely, that same invertebrate host species ranges off both Southeast Asia and North America. Another possibility, however improbable, is that cobia are astonishingly much more vagile than presently realized by ichthyologists, e.g., capable of Atlantic-Pacific migration or vice versa. Or, that $P$. anthicum has been introduced via aquaculture practices that 
translocated infected broodstock or juvenile cobia from the Gulf of Mexico to Vietnam or visa versa. That this blood fluke can mature in other fishes is unlikely because no record of it infecting another fish species exists in the literature and it was not detected during examinations of >2,000 individual fish comprising > 150 fish species from the Gulf of Mexico, Atlantic Ocean, and Pacific Ocean (Bullard, personal observations). Prior the present study and aside from Bullard and Overstreet (2006), only one additional report of a blood fluke infection in a cobia exists: Lebedev and Paruhkin (1972) reported a morphologically distinctive blood fluke, Psettarium rachycentri (Lebedev and Paruhkin, 1972) Bullard and Overstreet, 2006, from the kidney of cobia captured in the Gulf of Mannar, Indian Ocean. Further collections from cobias in the Pacific Ocean, Indian Ocean, and Gulf of Mexico could further test morphological and genetic variation among cobia blood flukes to shed light on this biogeography question. Moreover, the results of such studies may inform disease management decisions in the cobia aquaculture sector.

The principal pathological changes we observed in lesioned cobia heart were a thickened endocardium and large endocardial thrombi, which projected into the lumen of the heart and likely block normal blood flow (Figs. 5-10). Although we lack direct observations confirming that these thrombi can break free from the lesioned surface of the endocardium, we strongly suspect that they can, and do, based on the available histopathological evidence. Such emboli could cause acute mortalities resulting from infarcts (embolism), perhaps among cobia that present as normal. Such emboli would be particularly lethal to cobia during times of elevated cardiac output, e.g., during the grow-out phase and while feeding in a sea cage. Ogawa et al. (1989) attributed mortalities of heavily-infected cultured amberjacks to accumulation of eggs in the branchial arterioles that caused infarcts. They also reported the presence of 'papillate projections' in the wall of the afferent branchial arteries, comprising a proliferation of endothelial cells and edema of the tunica intima (Ogawa et al., 1989). Like in the present study, thrombi were documented, and, in severe cases, these pathological changes occluded blood vessels. Interestingly, however, the pathological changes we observed herein were limited to the endocardium and spongy myocardium, suggesting that the function of the outer, compact myocardium is unaffected even in heavily-infected cobia. Moreover, although cardiac myocytes can be hyperplastic or hypertrophic, we observed neither in compact myocardium; further suggesting that this portion of the heart is not affected by intense infections of this particular blood fluke. Nolan et al. (2016) detailed the histological picture of a remarkable, intense blood fluke infection in the heart of a marine fish from the Great Barrier Reef, Australia. These authors estimated that up to $30 \%$ of the total heart volume comprised the blood fluke. Similar to the present study, outward clinical signs of disease were lacking in the examined fish, but Nolan et al. (2016) speculated that the infection likely had a deleterious effect on the health of the heavilyinfected fish. In the present study, and perhaps in other intense blood fluke infections, the thickened endocardium of infected cobia may also be less efficient regarding respiratory gas exchange, thereby posing a threat to the cardiac myocytes of the spongy myocardium.

We speculate that disease problems associated with blood fluke infections in cobias have been overlooked in aquaculture settings, as few diagnosticians seemingly routinely examine the heart for non-bacterial and/or non-viral pathogens. For example, in the present case, we observed a $100 \%$ prevalence of infection and associated endocarditis. Future surveillance of sea cagereared cobias could reveal the presence of aporocotylidiasis related to the fibro-granulomatous endocarditis and endocardial thrombi described herein. For example, some reports of respiratory dysfunction (gaping) in cobias from aquaculture settings (Chu et al., 2013) could be due to 
intense blood fluke infections causing reduced cardiac output concomitant with branchial emboli. Moreover, we consider it probable that secondary bacterial and viral pathogens may use epithelial wounds resulting from miracidial hatching (in gill epithelium) or cercarial penetration (of skin) as portals of entry to gain access to the blood-vascular system. If the host outlives or kills the fluke, the body of the fluke (measuring up to $11 \mathrm{~mm}$ in body length [Bullard and Overstreet, 2006]) could itself be an embolus, if flushed from the heart.

Little information exists on how endocardial cells in fishes respond to fish blood fluke infections or, for that matter, how these cells respond to systemic infectious diseases more broadly. Poppe and Ferguson (2006) emphasized the fact that specialized endocardial cells ("scavenger endothelial cells") remove biological macromolecules and waste products from the blood vascular system, giving the fish heart some capacity as a regulator of systemic infectious disease. Because the normal endocardium in these cobia was seemingly obliterated, and in addition to reduced cardiac output and possible infarcts, we suspect that the severe endocarditis we document herein might also have a considerable deleterious effect on the physiological efficiency of the endocardium regarding its response to infectious disease. As such, we think that additional investigations on the interplay between blood fluke endocarditis and septicemias, for example, could reveal insights on blood flukes as pathogens in concert with bacterial or viral agents: blood fluke infections that obliterate the endocardium could amplify pathogenicity of systemic bacterial, viral, or fungal infections. Yet, the fish myocardium can repair itself (Poppe and Ferguson, 2006). We have seen young cobia (Gulf of Mexico) with endocardial scarring indicative of blood fluke infections but without adult flukes present, indicating that an outcome of infection is recovery and repair (Bullard, personal observations).

\section{Acknowledgments}

We thank Brittany Daniels, Jackson Roberts, and Matthew Womble (all APL) plus Dang Nguyen Anh Tuan, and Tran Quang Sang (Nha Trang University) for helping collect cobia and their parasites in Vietnam. This study is a contribution of the Southeastern Cooperative Fish Parasite and Disease Laboratory. It was supported in part by the York International Scholars Program (Auburn University, College of Agriculture) awarded to JRR, ROR, and SAB and by the National Science Foundation Division of Environmental Biology grant nos. 1112729, 1048523 and 1051106 awarded to SAB.

\section{References}

Aiken, H.M., Bott, N.J., Mladineo, I., Montero, F.E., Nowak, B.F., Hay-ward, C.J., 2007. Molecular evidence for cosmopolitan distribution of platyhelminth parasites of tunas (Thunnus spp.). Fish Fisher. 8, 167-180.

Aiken, H.M., Hayward, C.J., Nowak, B.F., 2015. Factors affecting abundance and prevalence of blood fluke, Cardicola forsteri, infection in commercially ranched southern bluefin tuna, Thunnus maccoyii, in Australia. Vet. Parasitol. 210, 106-113.

Anderson, G.R., Barker, S.C., 1998. Inference of phylogeny and taxonomy within the Didymozoidae (Digenea) from the second internal transcribed spacer (ITS2) of ribosomal DNA. Syst. Parasitol. 41, 87-94.

Benetti, D.D., O’Hanlon, B., Rivera, J.A., Welch, A.W., Maxey, C., Orhun, M.R., 2011. Growth rates of cobia (Rachycentron canadum) cultured in open ocean submerged cages in the Caribbean. Aquaculture 302, 195-201.

Benetti, D.D., Orhun, M.R., Sardenberg, B., O’Hanlon, B., Welch, A., Hoenig, R., Zink, I., Riveria, J. A., Denliger, B., Bacoat, D., Plamer, K., Cavalin, F., 2008. Advances in hatchery 
and grow-out technology of cobia Rachycentron canadum (Linnaeus). Aquac. Res. 39, 701711.

Blaylock, R., Bullard, S.A., 2015. Counter-insurgents in the Blue Revolution: Parasites, Diseases, and Perceptions. J. Parasitol. 100(6), 743-755.

Bullard, S.A., Overstreet, R.M., 2002. Potential pathological effects of blood flukes (Digenea: Sanguinicolidae) on pen-reared marine fishes. Proc. Gulf Caribb. Fish. Inst. 10-25.

Bullard, S.A., Goodwin, R., Goldstein, R., Overstreet, R.M., 2004. Cardicola forsteri (Digenea: Sanguinicolidae) from the heart of a northern bluefin tuna, Thunnus thynnus (Scombridae), in the Northwest Atlantic Ocean. Comp. Parasitol. 71, 245-246.

Bullard, S.A., Overstreet, R.M., 2006. Psettarium anthicum sp. n. (Digenea: Sanguinicolidae) from the heart of cobia Rachycentron canadum (Rachycentridae) in the Northern Gulf of Mexico. Folia Parasitol. 53, 117-124.

Bullard, S.A., Overstreet, R.M., 2008. Chapter 14: Digeneans as enemies of fishes. In: Fish Diseases. J. Eiras, H. Segner, T. Wahil, B. G. Kapoor (eds.). Sci. Publ., US, pages 817-976.

Bullard, S.A., Jensen, K., Overstreet, R.M., 2009. Historical account of the two family-group names in use for the single accepted family comprising the "fish blood flukes." Acta Parasitol 54(1), 78-84.

Bunkley-Williams, L., Williams, E.H., Jr., 2006. New records of parasites from culture cobia, Rachycentron canadum (Perciformes: Rachycentridae) in Puerto Rico. Rev. Biol. Trop. 54, 17.

Chen, S.C., Kou, R.J., Wu, C.T., Wang, P.C., Su, F.Z., 2001. Mass mortality associated with a Sphaerospora-like myxosporidean infestation in juvenile cobia, Rachycentron canadum (L.), marine cage culutured in Taiwan. J. Fish Dis. 24, 189-195.

Chu, K.B., Abdulah, A., Abdullah, S.Z., Bakar, R.A., 2013. A case study on the mortality of cobia (Rachycentron canadum) cultured in traditional cages. Trop. Life Sci. Res. 24(2), 7784.

Colquitt, S.E., Munday, B.L., Daintith, M., 2001. Pathological findings in southern bluefin tuna, Thunnus maccoyii (Castelnau), infected with Cardicola forsteri (Cribb, Daintith and Munday, 2000) (Digenea: Sanguinicolidae), a blood fluke. J. Fish Dis. 24, 225-229.

Crespo, S., Grau, A., Padrós, F., 1992. Sanguinicoliasis in the cultured amberjack Seriola dumerili Risso, from the Spanish Mediterranean area. Bull. Eur. Ass. Fish Pathol. 12, 157.

Cribb, T.H., Anderson, G.R., Adlard, R.D., Bray, R.A., 1998. A DNA-based demonstration of a three-host life-cycle for the Bivesiculidae (Platyhelminthes: Digenea). Int. J. Parasitol. 28, 1791-1795.

Cribb, T.H., Daintith, M., Munday, B., 2000. A new blood-fluke, Cardicola forsteri, (Digenea: Sanguinicolidae) of southern blue-fin tuna (Thunnus maccoyii) in aquaculture. Trans. R. Soc. S. Aus. 124, 117-120.

Eschmeyer W.N., R. Fricke, R. van der Laan (Eds.), Catalog of fishes, http://www.calacademy.org/scientists/projects/catalog-of-fishes, 2016 (accessed 09.11.2016).

Estrada, U.R., F.A. Yasumaru, A.G.J. Tacon, D. Lemos, 2015. Cobia (Rachycentron canadum): A selected annotated bibliography on Aquaculture, General Biology and Fisheries 19672015. Rev. in Fish. Sci. Aquac. 24(1), 1-97.

FAO. 2009. Fishstat plus Vers. 2.3.2000: Universal software for fishery statistical time series: Aquaculture production 1950-2007; Capture production 1950-2007. FAO Fish. Aquac. Dep., Fish. Inf., Data Stat. Unit. 
FAO. 2012. Cultured aquatic species information programme Rachycentron canadum (Linneaeus, 1766). Available from http://www.fao.org/fishery/culturedspecies/Rachycentron_canadum/en

Froese R., D. Pauly (Eds.), FishBase, World Wide Web electronic publication, www.fishbase.org, 2016 (accessed 09.11.2016).

Gonzalez, G., Garcia, A., Jover, M., Crespo, S., 1995. Influence of artificial food on 1+amberjack (Seriola dumerili, Risso) sanguinicoliasis and epitheliocystis. Bull. Eur. Ass. Fish Pathol. 15, 14-16.

Grau, A., 1994. Aspectos histológicos, ciclo reprodcutor y principales procesos patológicos de Seriola dumerili, Risso 1810 (Carangidae). PhD thesis, Universitat Autònoma de Barcelona.

Herbert, B.W., Shaharom, F.M., Anderson, I.G., 1995. Histopathology of cultured sea bass (Lates calcarifer) (Centropomidae) infected with Cruoricola lates (Trematoda: Sanguinicolidae) from Pulau Ketam, Malaysia. Int. J. Parasitol. 25, 3-13.

Huang, C.T., Miao, S., Nan, F.-H., Jung, S.-M. 2011. Study on regional production and economy of cobia Rachycentron canadum commercial cage culture. Aquacult. Int. 19, 649-664.

Kirk, R.S., Lewis, J.W., 1992. The laboratory maintenance of Sanguinicola inermis Plehn, 1905 (Digenea: Sanguinicolidae). Parasitology 104, 121-127.

Kirk, R.S., Lewis, J.W., 1993. The life cycle and morphology of Sanguinicola inermis Plehn, 1905 (Digenea: Sanguinicolidae). Syst. Parasitol. 25, 125-133.

Køie, M., 1982. The redia, cercaria and early stages of Aporocotyle simplex Odhner, 1900 (Sanguinicolidae): a digenetic trematode which has a polycheate annelid as the only intermediate host. Ophelia 21, 115-145.

Køie, M., Peterson, M.E., 1988. A new annelid intermediate host (Lanassa nordenskioeldi Malmgren, 1866) (Polychaeta: Terebellidae) for Aporocotyle sp. and a new final host family (Pisces: Bothidae) for Aporocotyle simplex Odhner, 1900 (Digenea: Sanguinicolidae). J. Parasitol. 74, 499-502.

Lebedev, V. I., Parukhin, A.M., 1972. [New sanguinicolids (Trematoda) of fish from the Gulf of Mannar (coast of India).] Biol. Nauki (MOsc.) 4, 7-14.

Liao, I. C., Huang, T.-S., Tsai, W.-S., Hsueh, C.-M., Chang, S.-L., Leaño, E.M., 2004. Cobia culture in Taiwan: current status and problems. Aquaculture 237, 155-165.

Littlewood, D.T.J., Olson, P.D., 2001. Small subunit rDNA and the phylum Platyhelminthes: signal, noise, conflict and compromise. In: Littlewood, D.T.J., Bray, R.A. (Eds.), Interrelationships of the Platyhelminthes. Taylor \& Francis, London, UK, pp 262-278.

Lockyer, A.E., Olson, P.D. and Littlewood, D.T.J., 2003. Utility of complete large and small subunit rRNA genes in resolving the phylogeny of the Neodermata: implications and a review of the cercomer theory. Biol. J. Lin. Soc. 78, 155-171.

Lowry, T., Smith, S. A., 2006. Mycobacterium sp. infection in cultured cobia (Rachycentron canadum). Bull. Eur. Ass. Fish Pathol. 26(2), 87-92.

McLean, E., Salze, G., Craig, S.R., 2008. Parasites, diseases and deformities of cobia. Ribarstvo 66(1), 1-16.

Montero, F.E., Azner, F.J., Fernandéz, M., Raga, J.A., 2003. Girdles as the main infection site for Paradeontacylix kampachi (Sanguinicolidae) in the greater amberjack, Seriola dumerili. Dis. Aquat. Org. 53, 271-272.

Munday, B.L., Hallegraeff, G.M., 1998. Mass mortality of captive southern bluefin tuna (Thunnus maccoyii) in April/May 1996 in Boston Bay, South Australia: A complex diagnostic problem. Fish Pathol. 33, 343-350. 
Munday, B.L., Sawada, Y., Cribb, T.H., Hayward, C.J., 2003. Diseases of tunas, Thunnus spp. J. Fish Dis. 26, 187-206.

Nhu, V.C., Nguyen, H.Q., Le, T.L., Tran, M.T., Sorgeloos, P., Dierchens, K., Reinersten, H., Kjørsvik, E., Svennevig, N., 2011. Cobia Rachycentron canadum aquaculture in Vietnam: Recent developments and prospects. Aquaculture 315:20-25.

Nolan, M.J., Cribb, T.H., 2006. Cardicola Short, 1953 and Braya n. gen. (Digenea: Sanguinicolidae) from five families of tropical Indo-Pacific fishes. Zootaxa 1265, 1-80.

Nolan, M.J., Cantacessi, C., Cutmore, S.C., Cribb, T.H., Miller, T.L., 2016. High-intensity cardiac infections of Phthinomita heinigerae n. sp. (Digenea: Aporocotylidae) in the orangelined cardinalfish, Taeniamia fucata (Cantor), off Heron Island on the Great Barrier Reef. Parasit. Int. 65, 371-377.

Ogawa, K., Egusa, S., 1986. Two new species of Paradeontacylix McIntosh, 1934 (Trematoda: Sanguinicolidae) from the vascular system of a cultured marine fish, Seriola purpurascens. Fish Pathol. 21, 15-19.

Ogawa, K., Fukudome, M., 1994. Mass mortality caused by blood fluke (Paradeontacylix) among amberjack (Seriola dumerili) imported to Japan. Fish Pathol. 29, 265-269.

Ogawa, K., Andoh, H., Yamaguchi, M., 1993. Some biological aspects of Paradeontacylix (Trematoda: Sanguinicolidae) infection in cultured marine fish Seriola dumerili. Fish Pathol. 28, 177-180.

Ogawa, K., Hattori, K., Hatai, K., Kubota, S., 1989. Histopathology of cultured marine fish, Seriola purpurascens (Carangidae) infected with Paradeontacylix spp. (Trematoda: Sanguinicolidae) in its vascular system. Fish Pathol. 24, 75-81.

Ogawa, K., Miyamoto, J., Wang, H.-C., Lo, C.-F., Kou, G.-H., 2006. Neobenedenia girellae (Monogenea) infection of cultured cobia Rachycentron canadum in Taiwan. Fish Pathology 41, 51-56.

Orélis-Ribeiro, R., Cribb, T.H., Halanych, K., Arias, C.R., Bullard, S.A., 2014. Diversity and ancestry of flatworms infecting the blood of non-tetrapod craniates. Adv. Parasitol. 85, 1-62.

Orélis-Ribeiro, R., Halanych, K.M., Dang, B.T., Bakenhaster, M.D., Arias, C.R., Bullard, S.A., in review. Two new species of Elopicola (Digenea: Aporocotylidae) from Hawaiian ladyfish, Elops hawaiensis (South China Sea) and Atlantic tarpon, Megalops atlanticus (Gulf of Mexico) with a comment on monophyly of elopomorph blood flukes. Parasitol. Int.

Overstreet, R.M., Curran, S.S., 2004. Defeating diplostomoid dangers in USA catfish aquaculture. Folia Parasitol. 51, 153-165.

Petersen, E.H., Luan, T.D., Chinh, D.T.M., Tuan, V.A., Binh, T.Q., Truc, L.V., Glencross, B.D., 2014. Bioeconomics of cobia, Rachycentron canadum, culture in Vietnam. Aquac. Econ. Manag. 18, 28-44.

Phinchongsakuldit, J., Chaipakdee, P., Collins, J.F., Jaroensutasinee, M., Brookfield, J.F.Y., 2013. Population genetics of cobia (Rachycentron canadum) in the Gulf of Thailand and Andaman Sea: fisheries management implications. Aquac. Int. 21, 197-217.

Poppe, T.T., Ferguson, H.W., 2006. Cardiovascular system. In: H. W. Ferguson (ed.), Systemic Pathology of Fish, A Text and Atlas of Normal Tissues in Teleosts and their Responses in Disease. Scotian Press, London, UK, pp. 140-167.

Shaffer, R.V., Nakamura, E.L., 1989. Synopsis of biological data on the cobia Rachycentron canadum (Pisces: Rachycentridae). NOAA Tech. Rep. NMFS 82, FAO Fish. Synop. 153. US Department of Commerce, $21 \mathrm{pp}$. 
Shirakashi, S., Tani, K., Ishimaru, K., Shin, S.P., Honryo, T., Uchida, H., Ogawa, K., 2016. Discovery of intermediate hosts for two species of blood flukes Cardicola orientalis and Cardicola forsteri (Trematoda: Aporocotylidae) infecting Pacific bluefin tuna in Japan. Parasitol. Int. 65, 128-136.

Thulin, J., 1980. A redescription of the fish blood-fluke Aporocotyle simplex Odhner, 1900 (Digenea, Sanguinicolidae) with comments on its biology. Sarsia 65, 35-48.

\section{Figure captions}

Figures 1-6. Specimens of Psettarium cf. anthicum Bullard and Overstreet, 2006 (Digenea: Aporocotylidae) from heart of cobia (Racycentron canadum) in sea cages in Nha Trang Bay, Vietnam. Scale bars $=500 \mu \mathrm{m}$. Ventral view. 1. Anterior end of adult voucher specimen USNM collection number XXXXXX, comprising esophagus (e), esophageal gland (eg), anterior ceca (ac), cecal bifurcation (cb), posterior ceca (pe), and rows of ventrolateral tegumental body spines (sr). Note that posteriorly the specimen appears girdled, which is the result of the host encapsulation constricting the body of the adult fluke, and that the extreme anterior end (anterior sucker) of the specimen is damaged. 2. Genitalia of adult voucher specimen USNM collection number XXXXXX, comprising posterolateral body protuberance, vas deferens (vd), seminal vesicle (sv), cirrus (ci), ovary (ov), oviduct (od), vitelline duct (vit), ootype (oo), ascending uterus (au), metraterm (met), and female genital pore (fp). 3. Genitalia of adult voucher specimen USNM collection number XXXXXX. 4. Genitalia of adult voucher specimen USNM collection number XXXXXX. 5. Bulbus arteriosus infected by an adult blood fluke (*) that is enveloped by the host encapsulation (arrows), comprising a tube-like endocardial thrombus. 6. Bulbus arteriosus infected by an adult blood fluke (*) (anterior end of adult fluke visible) that is enveloped by a host encapsulation. Note that sites of infection are associated with probable melanomacrophage aggregates and extensive, focal remodeling of endocardium.

Figures 7-18. Ultrastructural (scanning electron microscopy) and histopathological (hematoxylin and eosin sections) changes to heart of cobia (Rachycentron canadum) infected by Psettarium cf. anthicum Bullard and Overstreet, 2006 (Digenea: Aporocotylidae) from sea cages in Nha Trang Bay, Vietnam. Scale values aside each bar. 7. Thrombus (T), comprising an irregularly-shaped, knobby, dendritic mass extending from surface of endocardium. Note the apparent local effacement of the endocardium (*). 8. Thrombus (T), comprising an interconnected cluster of oblong to spheroid masses extending from surface of endocardium. 9. Thrombus (arrow), extending from endocardium and into lumen (L) of ventricle, including alteration of spongy myocardium (my) at thrombus base (tb). The thrombus includes remnants of adult specimen(s) of $P$. cf. anthicum (*). 10. Thrombi (arrows) obstructing lumen (L) of ventricle and comprising fibro-granulomatous masses that envelop fluke remnants $\left(^{*}\right)$ and that are associated with extensive alteration of endocardium and superficial layers of spongy myocardium (my). 11. Myocardial/endocardial granuloma (arrow) surrounding fluke remnants (*), including aggregates of melanin-like residue within and external to granuloma. 12. Myocardial/endocardial granuloma (arrow) surrounding fluke remnants. Note the seemingly normal and lesioned myocardium at left and right of field, respectively. 13. Higher magnification view of thrombus from Fig. 10. 14. Higher magnification view of thrombus from Fig. 11. 15. Fibrinous inflammation adjacent to granuloma surrounding fluke remnants in endocardium. 16. Extensive melanin-like pigment and lymphocytes in spongy myocardium. 17. A probable blood fluke egg (arrow) within an epitheliod granuloma in spongy myocardium. 18. Surface of thrombus depicted in Fig. 8; note that endocardial cells (ec) overlay apparent fibrinous inflammation (fi). 

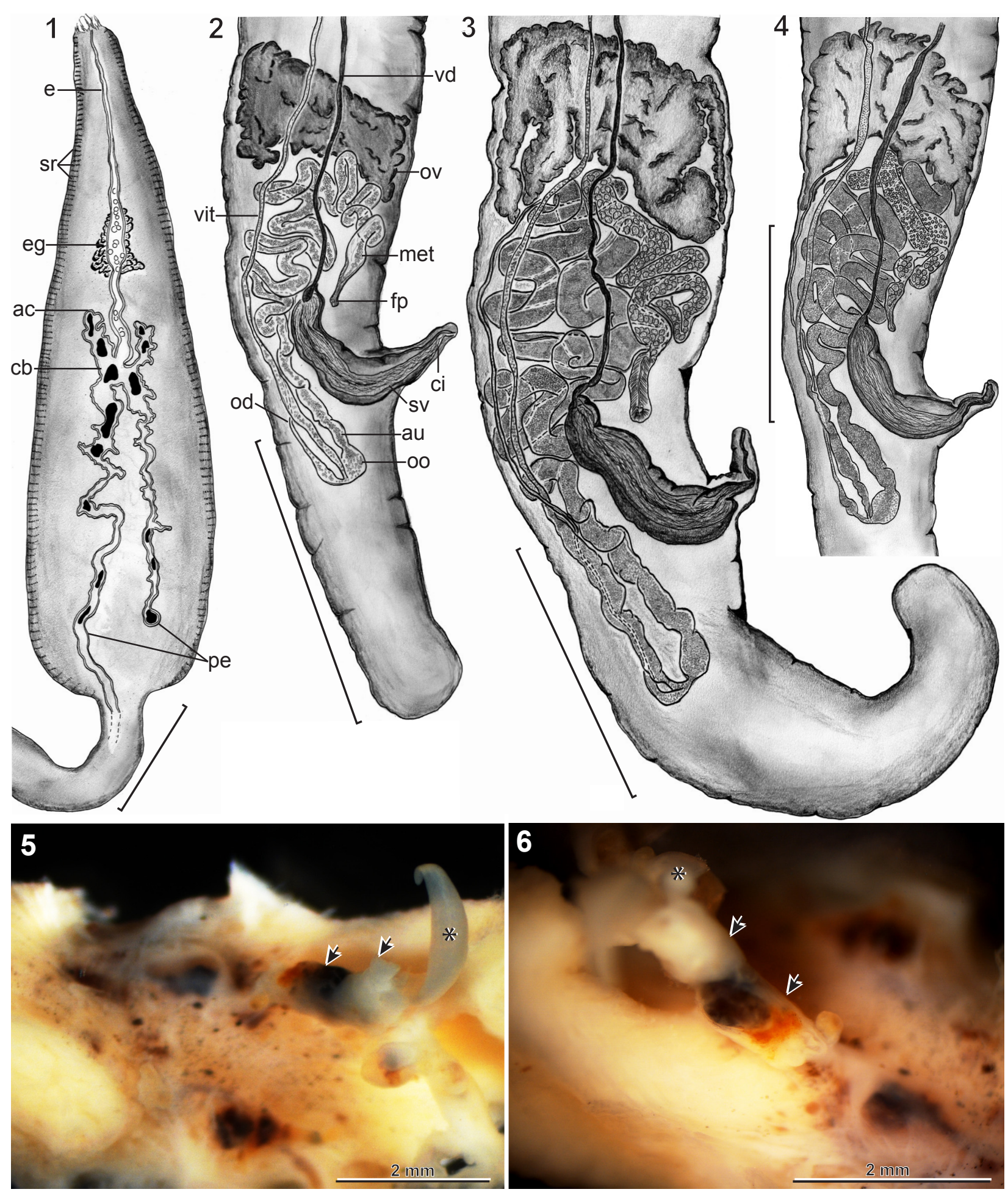

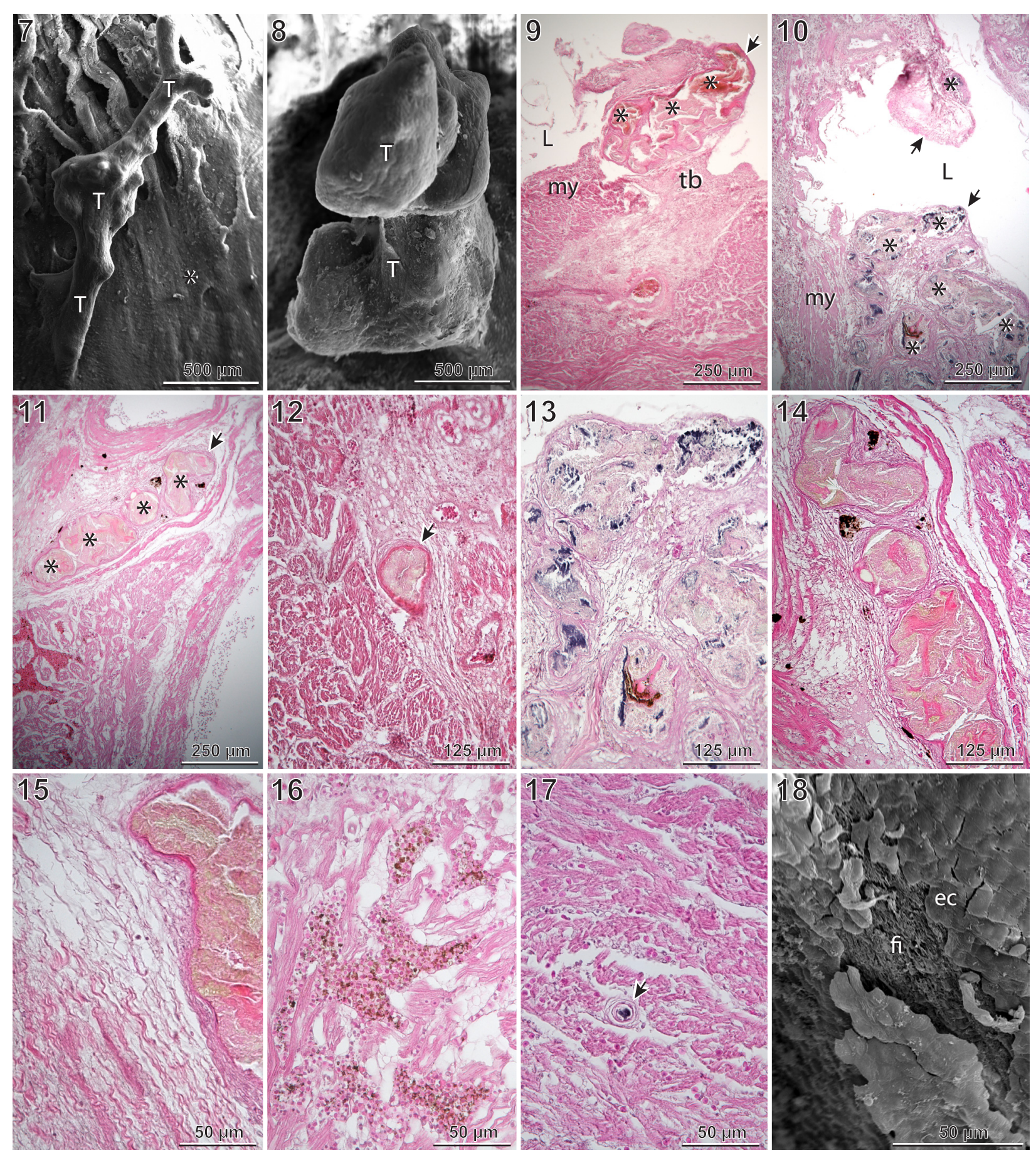